\title{
Avaliação da cobertura vacinal e internações por condições sensíveis à atenção primária preveníveis por imunização
}

\section{Evaluation of vaccination coverage and hospitalizations for conditions sensitive to primary care preventable by immunization}

Keyla Cristina Nogueira Durans, Julyana Suelen Rodrigues Fonseca, Jundson Dias Brito, Adryemerson Pena Forte Ferreira e Amanda Namíbia Pereira Pasklan

Como citar este artigo: DURANS, KEYLA C. N.; FONSECA, JULYANA S. R.; BRITO, JUNDSON D.; FERREIRA, ADRYEMERSON

P. F.; PASKLAN, AMANDA N. P. Avaliação da cobertura vacinal e internações por condições sensiveis à atenção primária preveniveis por imunização. Revista Saúde (Sta. Maria). 2021; 47.

Autor correspondente:

Nome: Keyla Cristina Nogueira Durans

E-mail: keyla.durans@discente.ufma.br Telefone: (98) 98527-8254 Formação: Graduanda em Enfermagem pela Universidade Federal do Maranhäo (UFMA), Pinheiro, MA, Brasil.

Filiação Institucional: Universidade Federal do Maranhão (UFMA),

Pinheiro, MA, Brasil.

Endereco: Rua Josias Abreu, $\mathrm{n}^{\circ} 42$

Bairro: Centro

Cidade: Pinheiro

Estado: Maranhão

CEP: 65200-000

Data de Submissão:

| 4/04/202 |

Data de aceite:

| |/06/202 |

Conflito de Interesse: Não há conflito de interesse

(cc) $\mathrm{BY}-\mathrm{NC}-\mathrm{ND}$

\section{RESUMO:}

Objetivo: Descrever o número de casos de notificações e de internações relacionado às condições imunopreveníveis sensíveis à Atenção Primária e compará-lo à cobertura vacinal do estado do Maranhão e do Brasil no período de 2010 a 2019. Métodos: Trata-se de um estudo descritivo, transversal, de natureza quantitativa, que utilizou dados disponíveis em bases secundárias sobre a Cobertura Vacinal (CV), morbidade por Doenças Preveníveis por Vacina e sobre as Internações por Condições Sensíveis à Atenção Primária (ICSAP), sendo analisado mediante software Microsoft Excel. Resultados: Como resultado, as CV apresentaram decréscimo no estado do Maranhão e a nível federativo, ambos a partir de 2015 , com os menores valores para as vacinas BCG, Hepatite A, Tríplice viral, Tetraviral e Poliomielite, importantes ao calendário básico infantil. Em relação às notificações de doenças, apresentaram aumento de casos: Coqueluche, Hepatite B e Tuberculose em ambas localidades, e o Sarampo predominantemente no Brasil a partir de 2018. A mesma tendência acompanha as ICSAP, com os maiores aumentos de internações pelas mesmas doenças supracitadas. Considerações Finais: Dados como esses demonstram a importância do acompanhamento da cobertura vacinal no país. Outrossim, ações de imunização, como a educação em saúde e investimento em insumos, podem contribuir para um maior crescimento e desenvolvimento da saúde no país, além de possivelmente diminuir os gastos despendidos em internações hospitalares.

PALAVRAS-CHAVE: Cobertura Vacinal; Internação Hospitalar; Doenças Preveníveis por Vacina; Notificação de Doenças.

\section{ABSTRACT:}

Objective: To describe the number of cases of notifications and hospitalizations related to immunopreventable conditions sensitive to Primary Care and compare them to the vaccination coverage in the state of Maranhão and Brazil in the period 2010-2019. Methods: This is a descriptive, cross-sectional, quantitative study, which used data available in secondary databases on Vaccine Coverage (CV), morbidity by Vaccine Preventable Diseases and on Hospitalizations for Primary Care-Sensitive Conditions (PCSCl), and was analyzed using Microsoft Excel software. Results: As a result, CVs showed a decrease in the state of Maranhão and at the federative level, both from 2015, with the lowest values for the BCG, Hepatitis A, Viral Triplet, Tetraviral and Poliomyelitis vaccines, important to the children's basic calendar. Regarding disease notifications, Pertussis, Hepatitis B and Tuberculosis showed increases in both locations, and measles predominantly in Brazil as of 2018. The same trend accompanies HCAls, with the largest increases in hospitalizations for the same aforementioned diseases. Final Considerations: Data such as these demonstrate the importance of monitoring vaccination coverage in the country. Furthermore, immunization actions, such as health education and investment in inputs, can contribute to greater growth and development of health in the country, and possibly reduce the costs spent on hospital admissions.

KEYWORDS: Vaccination Coverage; Hospitalization; Vaccine-Preventable Diseases; Disease Notification. 


\section{INTRODUÇÃO}

O ato de se vacinar é gratuito e voluntário no Brasil e constitui-se como uma atividade integrada, de baixa complexidade, porém, de relevante repercussão para erradicação-controle de doenças imunopreveníveis, caracterizadas como enfermidades que podem ser detidas de maneira competente e duradoura por meio da vacinação. A imunização colabora desta forma para uma consequente melhoria das condições gerais de saúde¹.

AOrganização Mundial da Saúde (OMS) elaborou o Plano de Ação Global para Vacinas 2011-2020, que congrega, entre seus objetivos gerais, o comprometimento dos países com a priorização das vacinações, para assim manter os êxitos já alcançados com o controle das doenças imunopreveníveis, objetivo esse reiterado pela Agenda $2030^{2}$.

Em sua edição comemorativa de 40 anos, em 2013, o Plano Nacional de Imunização (PNI) reconheceu questões a serem trabalhadas para sua melhor operacionalização, como a associação da vacinação à Atenção Primária em Saúde (APS); maior compromisso com a catalogação e análise dos dados para proporcionar real dimensão da situação do país; e permanente capacitação dos profissionais tanto para a prática da vacinação em si quanto para a devida educação em saúde, visando aumento homogêneo da Cobertura Vacinal $(C V)^{3,4}$.

Desde o início de sua catalogação no Sistema de Informação do PNI (SI-PNI), em meados de 1990 as CV mantinham-se em bons níveis (aproximadamente 95\%), demonstrando boa adesão aos serviços e imunobiológicos oferecidos. Entretanto, a partir do final de 2015 essas coberturas começaram a ter seus valores diminuídos no conjunto dos estados do país, sendo que, somente em 2019, sete vacinas apresentaram simultaneamente diminuição nas doses aplicadas no país, a maioria pertencente ao calendário infantil ${ }^{5}$.

A situação apresentada pode resultar em medo e piora do estado de saúde das pessoas acometidas e de seus familiares, e na repercussão em outros indicadores importantes para medir a qualidade da assistência na APS, como, por exemplo, as Condições Sensíveis à Atenção Primária (CSAP) $)^{6,7}$.

Condições sensíveis correspondem a questões relacionadas a morbidades que poderiam ter seu manejo e resolutividade apenas com ações desenvolvidas na APS, uma vez que feitas as intervenções adequadas. As CSAP são divididas em grandes grupos que incluem 19 causas de hospitalização e vários diagnósticos correspondentes, sendo que o grupo 1 corresponde às Doenças Preveníveis por Imunização e Condições Sensíveis ${ }^{6,7}$.

A nova configuração imposta pela COVID-19 altera o cenário dos serviços de saúde, tanto pela alta disseminação da doença com pouca disponibilidade de vacina até o momento, ou pela orientação de isolamento social que faz com que a busca pelas unidades de saúde seja diminuída. Além disso, profissionais que antes atuavam na frente de vacinação, podem ter sido realocados para serviços de combate à pandemia, como os de emergência, por exemplo. Essa realidade já pode ter seu reflexo contemplado em 24 países nos quais as campanhas de vacinação contra o Sarampo foram 
adiadas, deixando, segundo o Fundo das Nações Unidas para a Infância (UNICEF), mais de 117 milhões de crianças sem receber imunização contra o Sarampo ${ }^{8}$.

Ao mesmo tempo que essa situação perdura, as coberturas vacinais decrescem, trazendo à tona doenças imunopreveníveis como o Sarampo e a Gripe que podem ocasionar sobrecarga ainda maior nos serviços de saúde por sua necessidade de hospitalização, concomitantemente às pessoas acometidas pela COVID-199.

O objetivo deste estudo foi descrever o número de casos de notificações e de internações relacionadas às CSAP e compará-las à CV do estado do Maranhão e do Brasil, partindo da hipótese de que a CV pode reduzir os casos de internações por doenças imunopreveníveis. Sendo assim, torna-se relevante fornecer dados que permitam o estudo sobre os indicadores de vacinação, morbidade e internação por causas preveníveis com a vacina.

\section{MÉTODO}

Trata-se de um estudo descritivo, transversal, de natureza quantitativa, que utilizou dados disponíveis em base de dados secundários sobre a CV, morbidade por Doenças Imunopreveníveis e sobre as Internações por CSAP. O conjunto de dados coletados compreende informações referentes ao estado do Maranhão e Brasil, no período de 20102019.

Os dados sobre a CV foram coletados a partir do sítio eletrônico do Departamento de Informática do SUS (Datasus) (www.datasus.gov.br), disponíveis nos registros do SI-PNI, no período de setembro de 2020 a janeiro de 2021, compreendendo os imunobiológicos do calendário básico, excetuando-se as vacinas pertencentes apenas ao calendário da gestante, disponíveis pelo período selecionado. Para o cálculo da cobertura de imunobiológicos que apresentam CV completa com mais de uma dose, como é o caso da vacina SRC, Poliomielite, Pneumocócica 10, Meningocócica C e DTP, foi utilizada a média aritmética simples.

Cada vacina apresenta uma meta de CV individual que deverá ser utilizada como parâmetro de comparação entre os anos. Para as vacinas Influenza e HPV CV $\geq 80 \%$; $\geq 90 \%$ para BCG e VORH; para vacinas da Poliomielite, Tétano, Coqueluche, Difteria, Haemophilus, Hepatite A e B, Pneumocócica 10, Meningocócica C, Tríplice e Tetraviral $\geq 95 \%$, e de $100 \%$ para Febre Amarela, Dupla Adulto e DTpa, do calendário da gestante 3,10 .

Os dados epidemiológicos, à exceção do Sarampo, também foram retirados do mesmo sítio. Os agravos imunopreveníveis que constam na plataforma são: Hepatite B, Tuberculose, Difteria, Tétano Neonatal e Acidental, Coqueluche, Meningite, e as Doenças Exantemáticas. Os dados relativos ao Sarampo foram retirados de boletins epidemiológicos divulgados periodicamente pelo $\mathrm{MS}^{11}$.

Para coleta de informações referentes às ICSAP, foi acessada a aba do Sistema de Informações Hospitalares do SUS (SIH). Os arquivos disponíveis para tabulação correspondem às Autorizações de Internações Hospitalares (AlH) e 
são disponibilizadas por unidade de federação e ano.

Como critérios de inclusão para a coleta de dados, entraram no estudo somente achados das doenças imunopreveníveis, CV e internações por condições sensíveis à imunização com registros nos bancos de dados nacionais que estiverem inclusos no período estudado (2010-2019), excluindo-se fontes como relatórios municipais e dados primários.

Após coletadas, as informações foram tabuladas em planilhas do Excel, e posteriormente analisadas pelo mesmo programa. Os resultados estão dispostos por meio de tabelas e gráficos, facilitando assim a visualização.

Este estudo faz parte do projeto maior intitulado: "Análise do serviço de imunização e da cobertura vacinal no município de Pinheiro (MA): Atenção Primária à Saúde em Imunização", submetido ao Comitê de Ética em Pesquisa da Universidade Federal do Maranhão (UFMA), aprovado sob parecer de número 4.098.742, estando de acordo com a Resolução 466/12 do Conselho Nacional de Saúde.

\section{RESULTADOS}

Este estudo buscou levantar os dados correspondentes a CV, notificações por condições relacionadas à vacinação e a sua consequente internação também por condições sensiveis a imunização, no período de 2010-2019 para CV e ICSAP, e nos anos 2010 e 2019 para as notificações, a fim de permitir a observação e comparação dos dados disponíveis no Brasil e no estado do Maranhão.

Em relação à CV total, tanto no Maranhão quanto a nível nacional, apenas o ano de 2015 alcançou $90 \%$ da meta, ultrapassando inclusive esse valor. Nos anos de 2012 e 2013 os valores estiveram dentro da faixa dos $70 \%$. A partir de 2016 as CV apresentaram maior declínio, atingindo percentuais próximos ou abaixo dos 60\% na cobertura total (Tabela 1).

Comparando-se os anos de 2011 (maior CV) e 2016 (menor CV) quanto à cobertura por imunobiológico, observase que, em 2011, as vacinas BCG, Poliomielite e Tríplice Viral exibiram valores que ultrapassavam $100 \%$ de cobertura no estado. Estes mesmos imunobiológicos no ano de 2016 pontuaram valores abaixo da meta de CV no Maranhão. (Tabela 1).

A nível de Brasil, à exceção de 2015, os demais anos estudados compreendem valores na faixa de $70 \%$, e a menor CV total ocorreu no ano 2016. Comparando-se a CV por imunobiológico entre os anos 2015 e 2016, podemos constatar diminuição de aproximadamente todas as vacinas do calendário, com maior enfoque nas vacinas da Tetraviral $(-30,49 \%)$, Hepatite A $(-24,62 \%)$ e BCG $(-8,75 \%)$ (Tabela 1). 
Tabela 1: Cobertura Vacinal por imunobiológico e total, segundo o DATASUS. Maranhão e Brasil, 2010-2019.

\begin{tabular}{|c|c|c|c|c|c|c|c|c|c|c|}
\hline \multirow{2}{*}{$\begin{array}{c}\text { VACINAS } \\
\text { (COBERTURA } \\
\text { POR } \\
\text { LOCALIDADE) }\end{array}$} & \multicolumn{10}{|c|}{ ANO DA ANÁLISE E COBERTURA VACINAL (\%) } \\
\hline & 2010 & 2011 & 2012 & 2013 & 2014 & 2015 & 2016 & 2017 & 2018 & 2019 \\
\hline \multicolumn{11}{|l|}{ BCG } \\
\hline MA & 126 & 122,7 & 114 & 113,4 & 108,1 & 109,1 & 96,3 & 105,7 & 105,1 & 81,2 \\
\hline BR & 106 & 107,9 & 105,6 & 107,4 & 107,3 & 103 & 94,3 & 97,9 & 99,7 & 84,8 \\
\hline \multicolumn{11}{|l|}{ HEPATITE B } \\
\hline MA & 100 & 97 & 97,4 & 100,1 & 92 & 92,5 & 75,2 & 83,8 & 87,9 & 66,7 \\
\hline BR & 96 & 97,7 & 96,6 & 100,5 & 92,4 & 90,5 & 84 & 85,1 & 88,4 & 73,2 \\
\hline \multicolumn{11}{|l|}{ POLIOMIELITE } \\
\hline MA & 106,6 & 102,9 & 97,5 & 100,7 & 87,1 & 62,5 & 46,6 & 57,2 & 58,7 & 59 \\
\hline BR & 99,3 & 101,3 & 96,5 & 96,8 & 91,5 & 67,2 & 63,5 & 73,5 & 75,3 & 73,2 \\
\hline \multicolumn{11}{|c|}{ VACINA ORAL ROTAVÍRUS HUMANO (VORH) } \\
\hline MA & 72,8 & 77,8 & 79,2 & 88,9 & 87,7 & 87,6 & 75,3 & 72,1 & 82,8 & 75,9 \\
\hline BR & 83 & 87 & 86,3 & 93,5 & 93,4 & 90,6 & 87,6 & 85,1 & 91,3 & 83,3 \\
\hline \multicolumn{11}{|l|}{ PENTAVALENTE } \\
\hline MA & - & - & 23,8 & 96,4 & 89,1 & 86,7 & 74,1 & 73,6 & 80,6 & 57,7 \\
\hline BR & - & - & 24,8 & 95,8 & 94,8 & 90,6 & 87,9 & 84,4 & 88,4 & 69,3 \\
\hline \multicolumn{11}{|c|}{ PNEUMOCÓCICA 10} \\
\hline MA & 0,9 & 50,7 & 76,2 & 83,6 & 77,5 & 74,5 & 71,4 & 75,3 & 81,2 & 78,1 \\
\hline BR & 24 & 81,6 & 88,3 & 93,3 & 90,7 & 84,7 & 85,1 & 84,2 & 88,6 & 84,5 \\
\hline \multicolumn{11}{|c|}{ MENINGOCÓCICA C } \\
\hline MA & 2,2 & 70,5 & 89,1 & 93,7 & 81,5 & 79,3 & 74,2 & 74,2 & 74,1 & 76,1 \\
\hline BR & 26,8 & 105,6 & 96,1 & 99,7 & 92,4 & 86,7 & 88 & 83 & 84,3 & 84,6 \\
\hline \multicolumn{11}{|c|}{ FEBRE AMARELA } \\
\hline MA & 104,6 & 101,5 & 100,6 & 99,3 & 88,4 & 79,4 & 69,6 & 65,8 & 72,3 & 65,3 \\
\hline BR & 49,2 & 48,5 & 49,3 & 51,5 & 46,8 & 46,5 & 41,7 & 47,3 & 59,5 & 61 \\
\hline \multicolumn{11}{|l|}{ HEPATITE A } \\
\hline MA & - & - & - & - & 43,4 & 83,1 & 51,4 & 68,1 & 70,6 & 72,9 \\
\hline BR & - & - & - & - & 60,1 & 88,5 & 63,9 & 78,9 & 82,6 & 83,3 \\
\hline \multicolumn{11}{|c|}{ SARAMPO CAXUMBA E RUBÉOLA (SCR) } \\
\hline MA & 110 & 112,8 & 98,2 & 76,2 & 106,5 & 72,7 & 58,1 & 64,7 & 70,4 & 75,2 \\
\hline BR & 99,9 & 102,3 & 99,5 & 88,1 & 102,8 & 77,6 & 78 & 79,6 & 84,7 & 85,4 \\
\hline \multicolumn{11}{|c|}{ SARAMPO CAXUMBA RUBÉOLA VARICELA (SCRV) } \\
\hline MA & - & - & - & 23,4 & 87,4 & 59,5 & 8,11 & 21,3 & 15,4 & 6,91 \\
\hline BR & - & - & - & 34,2 & 90,2 & 57,8 & 27,3 & 35,4 & 33,2 & 33.6 \\
\hline \multicolumn{11}{|c|}{ DIFTERIA TÉTANO PERTUSSIS (DTP) } \\
\hline MA & 104,3 & 100,3 & 86,7 & 102,3 & 57,5 & 58,5 & 48,5 & 54,2 & 70,8 & 39,5 \\
\hline BR & 98 & 99,6 & 93,8 & 94,4 & 61,4 & 63,9 & 71,6 & 69,2 & 54,2 & 54,6 \\
\hline \multicolumn{11}{|l|}{ CV TOTAL } \\
\hline MA & 87 & 87,1 & 77,6 & 73,5 & 83,2 & 94,4 & 43,38 & 64,3 & 68,1 & 63,2 \\
\hline BR & 74,6 & 85,3 & 77,3 & 73,2 & 86,3 & 95 & 50,4 & 72,9 & 77,1 & 73,4 \\
\hline
\end{tabular}

Fonte: DATASUS - PNI

No Gráfico 1, verificamos as notificações de doenças imunopreveníveis, com comparação feita dos anos de 2010 e 2019, que aponta aumento no número de casos notificados para os seguintes agravos no estado do Maranhão: 
Coqueluche (aumento de 16 casos), Hepatite B (aumento de 118 casos) e Tuberculose (aumento de 181 casos). Os demais agravos apresentaram estabilidade (Tétano Acidental) ou declínio (Tétano Neonatal, Meningite e Difteria).

Federativamente, as notificações apresentaram aumento para os mesmos agravos a nível estadual: Coqueluche (782 novos casos), Hepatite B (211 casos) e Tuberculose (5.675 novos casos). Os casos para Tétano Neonatal e Acidental, Meningite e Difteria tiveram diminuição de notificações. Observa-se que os dados referentes às doenças exantemáticas (Sarampo, Rubéola e Caxumba) aparecem somente em 2010 e sem valores adicionados para o ano de 2019 (Gráfico 1).

Gráfico 1: Casos notificados referentes às doenças imunopreveníveis. Maranhão e Brasil, 2010 e 2019.

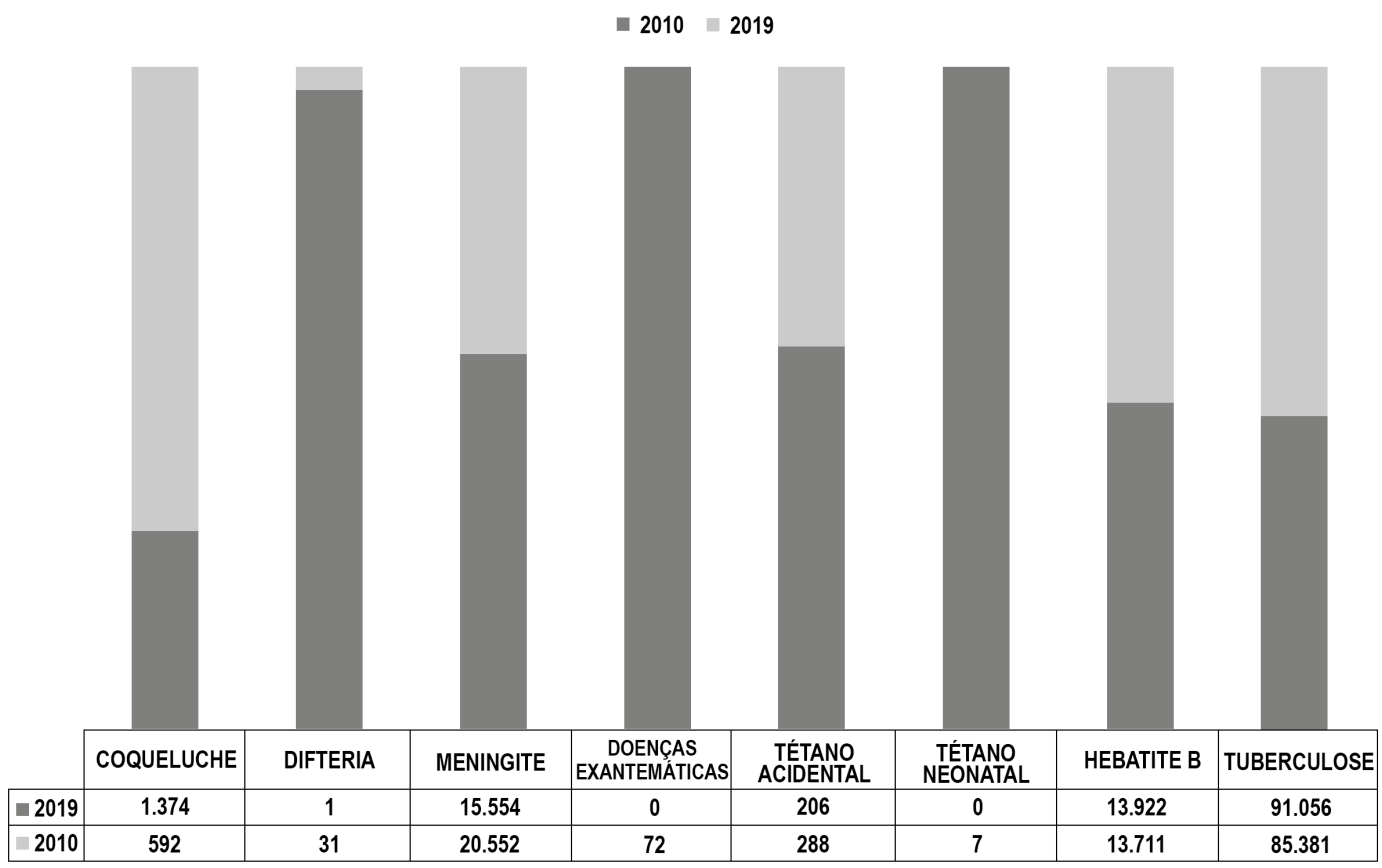

\section{BRASIL}

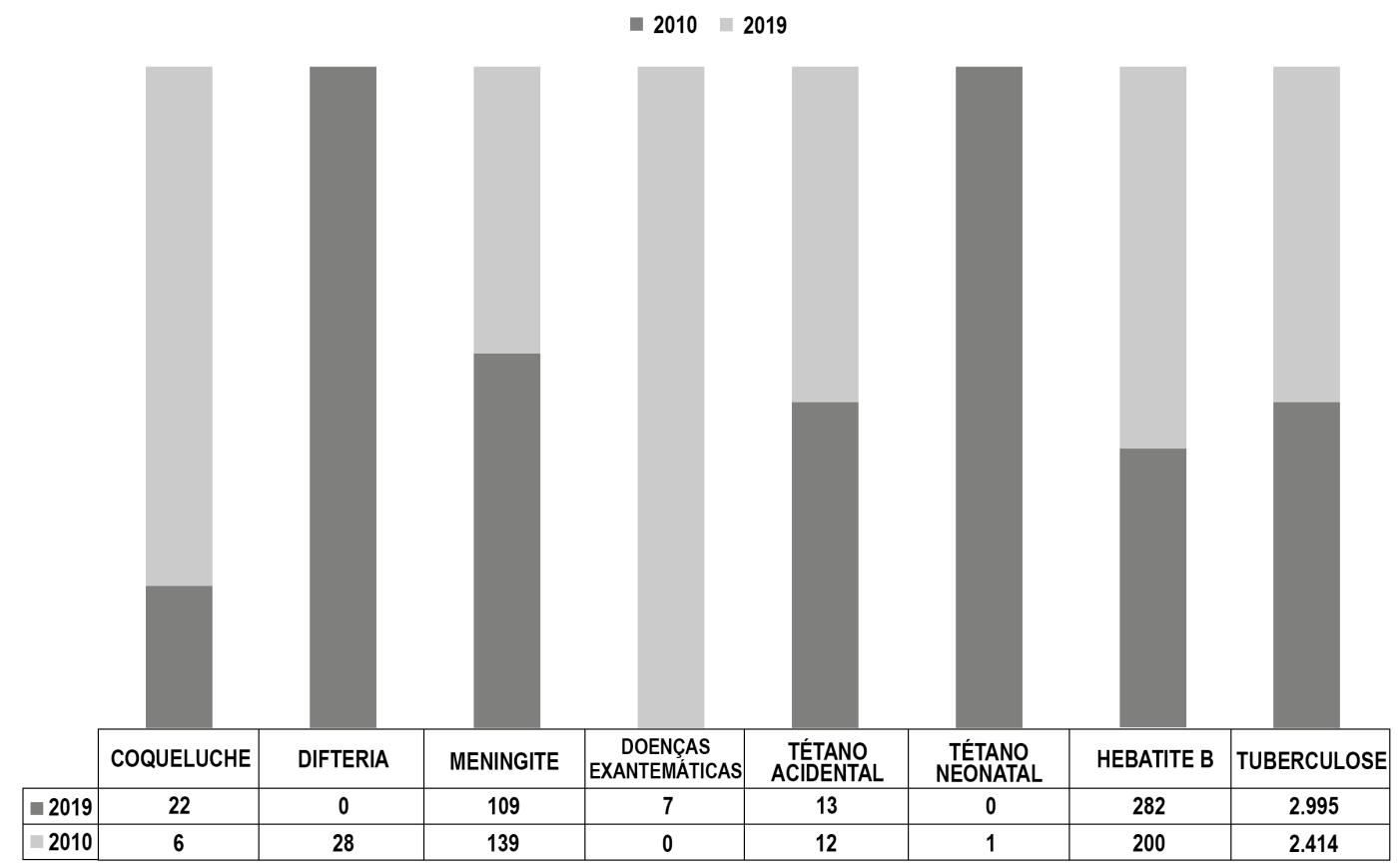

MARANHÃO 
O gráfico 2 e a Tabela 2 apresentam os registros correspondentes às ICSAP. No estado do Maranhão, de 2010 a 2019 foram realizadas 3.000 novas internações, caracterizadas por uma escalada crescente de casos entre os anos estudados. Em 2014 atingiu-se mais de 300 internações, e os demais anos apresentaram crescimento nessa faixa, até culminar no ano com maior quantidade de internações no estado, em 2019.

Os números relativos ao Brasil expressam uma média de 20-25 mil internações por ano, totalizando 225.490 ocupações de leito. 0 único ano que não alcançou esta faixa foi 2010, e o ano com maior agrupamento foi o de 2012 (Gráfico 2).

Gráfico 2: Internações por CSAP, correspondentes ao grupo de doenças preveníveis por imunização. Maranhão e Brasil, 2010-2019.

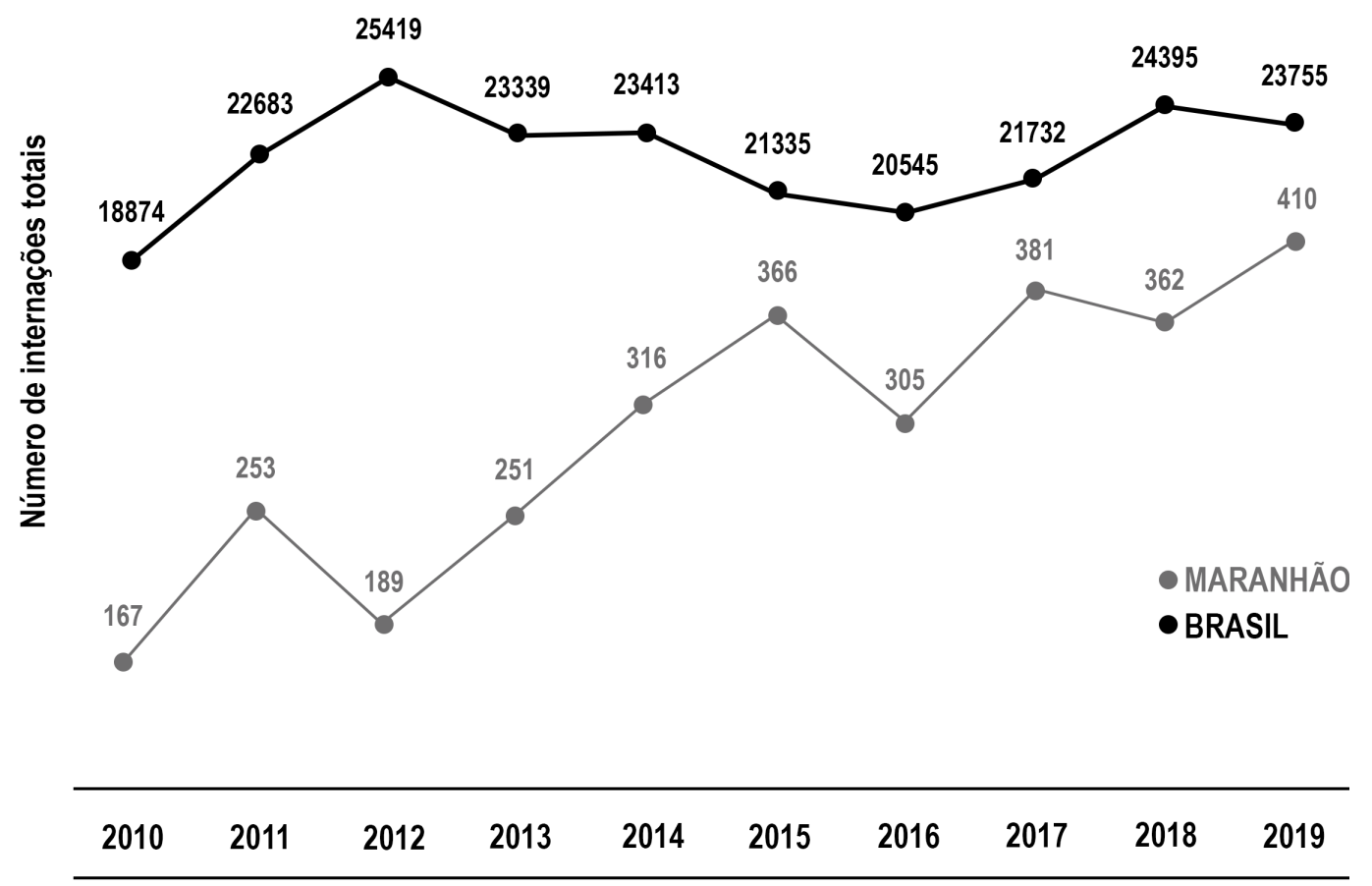

O estado do Maranhão contém, em toda série temporal, a maioria dos casos de internação por Tuberculose, seguido de Hepatite B e Coqueluche. Já no Brasil, as causas básicas das internações variaram de acordo com o ano: de 2010 a 2017 a Tuberculose, Hepatite B e Coqueluche obtiveram números mais expressivos, mas, a partir de 2018, junto a estas doenças, houve aumento de hospitalizações por Febre Amarela (1003 casos) e, em 2019, o Sarampo desponta com 833 registros (Tabela 2). 
Tabela 2: Taxa correspondente às Internações por CSAP, relacionadas à Tuberculose, Hepatite B, Coqueluche, Febre Amarela e Sarampo. Maranhão e Brasil, 2010-2019.

\begin{tabular}{cccccccccccc}
\hline ICSAP - POR & \multicolumn{7}{c}{ ANO DA ANÁLISE E TAXA DO TOTAL AO ANO (\%) } \\
\cline { 2 - 11 } LOCALIDADE & $\mathbf{2 0 1 0}$ & $\mathbf{2 0 1 1}$ & $\mathbf{2 0 1 2}$ & $\mathbf{2 0 1 3}$ & $\mathbf{2 0 1 4}$ & $\mathbf{2 0 1 5}$ & $\mathbf{2 0 1 6}$ & $\mathbf{2 0 1 7}$ & $\mathbf{2 0 1 8}$ & $\mathbf{2 0 1 9}$ \\
\cline { 2 - 11 } TUBERCULOSE & & & & & & & & & & \\
MA & 81,4 & 78,6 & 74,6 & 71,7 & 51 & 61,4 & 80,6 & 82,4 & 85,5 & 85,6 \\
BR & 85,5 & 86,3 & 81,7 & 78 & 72,4 & 82,2 & 86,7 & 84,1 & 80,1 & 84,8 \\
HEPATITE B & & & & & & & & & & \\
MA & 8,9 & 9,1 & 18 & 7,5 & 2,2 & 3,2 & 4,9 & 4,2 & 4,4 & 2,6 \\
BR & 8,8 & 6,2 & 4,8 & 4,8 & 4,5 & 4,6 & 5,1 & 4,7 & 4,3 & 4,1 \\
COQUELUCHE & & & & & & & & & & \\
MA & 1,8 & 6,7 & 4,7 & 18 & 44,3 & 30,8 & 6,5 & 9,2 & 7 & 7,8 \\
BR & 2,3 & 6,3 & 11,8 & 15,4 & 21 & 10,9 & 5,5 & 5,5 & 5,9 & 5,1 \\
FEBRE AMARELA & & & & & & & & & & \\
MA & 0 & 0,4 & 0 & 0 & 0 & 0 & 4,2 & 0,79 & 0,28 & 0 \\
BR & 0,1 & 0,09 & 0,08 & 0,05 & 0,04 & 0,06 & 0,1 & 3,4 & 4,1 & 0,37 \\
SARAMPO & & & & & & & & & & \\
MA & 0 & 0 & 0 & 0,80 & 0 & 0 & 0,33 & 0 & 0,55 & 0,49 \\
BR & 0,34 & 0,31 & 0,25 & 0,32 & 0,35 & 0,26 & 0,16 & 0,29 & 3,6 & 3,5
\end{tabular}

Fonte: SIH-SUS

\section{DISCUSSÃO}

Entre os anos de 2015 e 2016, o Brasil recebeu da OPAS os certificados de erradicação da Rubéola e Síndrome da Rubéola Congênita, e de diminuição da circulação dos vírus do Sarampo em 2016. Como reflexo disso, as taxas de morbimortalidade infantil diminuíram ${ }^{3,12}$.

A continuidade deste progresso depende diretamente da manutenção de taxas de CV adequadas. As vacinas que se apresentaram abaixo da meta durante todo o período do estudo, no estado do Maranhão, foram: VORH, Pneumocócica 10, Meningocócica C, Hepatite A e Tetraviral. As vacinas contra Poliomielite, Pentavalente, Febre Amarela e DTP iniciaram queda a partir do ano de 2014 e, a vacina Tríplice Viral, a partir de 2015.

Os achados corroboram com pesquisas realizadas no Maranhão, em que se observou que a maior parte do calendário vacinal infantil apresentava atraso, com notoriedade para as vacinas Meningocócica, Pneumocócica e Tetraviral. Além disso, levantou-se que os maiores motivos para não-vacinação por parte dos responsáveis foram: criança fora da faixa etária, criança doente no momento da vacinação, esquecimento, recusa vacinal e falta de imunobiológico na UBS ${ }^{13,14}$.

No Brasil, os resultados não foram distintos, sendo que Hepatite B, Poliomielite, Pentavalente e Meningocócica apresentaram queda a partir de 2014; Pneumocócica, Febre Amarela, Hepatite A, e Tetraviral durante todo o período do estudo; e, por fim, Tríplice Viral e DTP tiveram coberturas inadequadas a partir de 2015 e 2012, respectivamente.

Alguns fatores podem auxiliar na queda da CV: a propagação de notícias falsas sobre a efetividade das vacinas 
e os danos da vacinação. A internet tornou- se uma grande facilitadora do movimento antivacina, no qual páginas são utilizadas para disseminar inverdades que refutam estudos científicos que comprovam a eficácia da vacinação ${ }^{15}$. Tais ações podem levar a hesitação vacinal, que é definida como o atraso em aceitar as vacinas ou a sua total recusa ${ }^{16}$.

Outro fator que pode estar atrelado a menores índices vacinais é a alimentação incorreta do SI-PNI. Apesar de ser um avanço e contribuir para a simplificação dos registros, bem como o monitoramento da CV, o sistema ainda enfrenta alguns entraves tocantes ao domínio da tecnologia, falta de qualificação dos profissionais que operam os sistemas, custos de tecnologia, custeio do sistema e proteção das informações, conexão lenta à internet e a não padronização do sistema ${ }^{17,18}$.

A análise feita entre os anos de 2010-2019 demonstrou que a maioria dos quadros de internação por CSAP no Maranhão foi em decorrência da Coqueluche, Hepatite B e Tuberculose. Em 2019, o Maranhão atingiu o seu ápice de internações, onde $7,8 \%$ do total era por Coqueluche, ficando acima da média brasileira (5,1\%). Essa alta taxa de internação, principalmente em menores de 1 ano, revela um alto risco de mortalidade por Coqueluche, que varia entre $0.8 \%$ e $6,7 \%{ }^{19}$.

Este expressivo aumento está associado a baixa CV, iniciada a partir de 2014, principalmente na vacina DTP, ao esquema vacinal incompleto e a não ampliação da vacina dTpa aos adolescentes e adultos, visto que o calendário vacinal não contempla essas faixas etárias. Menores de um ano são os mais acometidos, e tal achado elucida o fato já apontado pela literatura, que menores de seis meses encontram-se com elevada incidência e letalidade mais evidenciada, pois encontram-se desprotegidos pela não imunização no tempo adequado, o que implica em mutações no DNA do patógeno, favorecendo o ressurgimento da doença ${ }^{20}$.

Sobre a Hepatite B, no período de 1999 a 2019, foram registrados 247.890 casos, tendo suas taxas de detecção com tendência de queda no intervalo de 2015 a 2019, chegando inclusive em 6,6 casos para cada 100 mil habitantes, sendo a região Nordeste, entre 2009 e 2019, a região com mais baixas taxas de detecção no país, valores inferiores a 4,0 casos para cada 100 mil habitantes nesse intervalo21. Esse resultado pode estar fortemente relacionado à experiência exitosa de vacinação brasileira contra as hepatites até o ano de $2015^{21}$.

No entanto, a partir do ano 2016, se observa nos resultados deste estudo a redução progressiva das CV da Hepatite $B$, além da inadequação de CV para Hepatite A em todos os anos ${ }^{22}$. Como consequência, poderá causar 0 aumento dessas notificações ao longo dos anos de 2019 e 2020 que ainda não possuem dados consolidados, inclusive permitindo o aumento dos óbitos.

No presente estudo, houve queda na CV para a vacina BCG no período de 2010 a 2019. A vacinação é um dos principais métodos de prevenção da Tuberculose no país, sobretudo na infância, e, por essa razão, a melhoria nas CV de BCG são fundamentais para uma mudança definitiva de cenários, pois estudos apontam que a vacinação primária pode oferecer proteção parcial contra a infecção pelo Mycobacterium tuberculosis possuindo eficácia que varia de 0 a $80 \%$ 
com potencial para reduzir a incidência de Tuberculose disseminada ${ }^{23}$.

Houve aumento do número de hospitalizações para tratamento de Tuberculose no período de 2006 a 2015 , apesar de uma taxa de mortalidade ainda estável. Observou-se também que, dos pacientes com Tuberculose ativa, $14 \%$ foram internados em hospitais para tratamento ${ }^{24}$. Apesar de o país caminhar para uma progressiva redução de internação por esta causa a partir de 2015, o Nordeste ainda concentra a maior parte dos gastos hospitalares do país por Tuberculose, com valor total próximo a 6.881.786,51 reais entre 2010-201925.

Nos últimos anos da nossa análise, nos deparamos com o aumento dos casos notificados por sarampo, prevenido pela vacina Tríplice Viral. Assim como em nosso estudo, é observado por outro autor ${ }^{26}$ a queda vacinal constante a partir de 2014, seguido de um aumento proporcional de casos notificados. A junção desses fatos contribuiu para que o Brasil perdesse, em 2019, o certificado conferido pela OPAS de país livre do sarampo ${ }^{27}$.

As internações por Sarampo nos últimos anos se intensificaram e trouxeram consigo debates sobre o aumento dos movimentos antivacina na região Sudeste, falta de informações sobre os imunizantes para a população e o movimento imigratório de venezuelanos pelo estado de Roraima, sem possibilidade de confirmação do seu estado vacinal28, 29 .

Entre 2018 e 2019, período considerado de surto de Sarampo, cerca de 1.724 casos que necessitaram de internação foram cadastrados no SIH, mostrando o curso negativo da doença quando as condutas adequadas para sua prevenção não são efetivadas, visto que não existe tratamento específico para o Sarampo. A maioria foi observada nas regiões Norte e Sudeste, com maior quantidade de casos ( $66 \%$ dos casos) na faixa etária de 0 a 5 anos, revelando uma possível fragilidade nas ações de vacinação ${ }^{30}$.

\section{CONSIDERAÇÕES FINAIS}

Constata-se através dos resultados deste estudo que as coberturas vacinais apresentam constante declínio a partir do ano de 2015, sobretudo àquelas pertencentes ao calendário infantil, a exemplo da Poliomielite, Tetraviral, BCG, Tríplice Viral e Hepatite A. Contempla-se juntamente a isso a ascensão das notificações e internações por agravos que poderiam ter sido prevenidos por meio de ações de imunização.

Dados como esses ascendem a necessidade de observação mais cuidadosa e estudos com desenhos mais complexos acerca da vacinação no país, a fim de entender os motivos que levam ao decréscimo das coberturas vacinais, entendendo-se que a vacinação em massa proporciona ambiente desfavorável ao retorno de doenças imunopreveníveis já erradicadas ou controladas e reflete na diminuição de suas internações.

Diante desses achados, pode-se elencar como pontos fortes desta pesquisa a capacidade de acompanhamento longitudinal de 3 características diferentes (CV, internações e notificações), proporcionado pela ampla catalogação de dados pelas plataformas do MS, permitindo a observação das tendências relacionadas a estas variáveis. Como maior 
limitação está o maior esforço para extração e análise dos bancos nas plataformas, devido à falta de padronização de algumas das variáveis, demandando um tempo maior para a correta interpretação dos resultados. Além disso, o estudo utilizou dados secundários, que são passíveis de subnotificação e erros de preenchimento, porém ainda assim refletem a realidade da CV no país.

Em face disso, estudos como este podem colaborar para um maior conhecimento em relação às condições de vacinação da população, assim como sua influência nas internações por estas causas, servindo de escopo para futuras análises que tratam sobre este tema. Ademais, possibilita auxiliar na definição de possíveis estratégias, como ações de educação em saúde que podem ser desenvolvidas em diferentes esferas de governo, com vistas tanto à promoção do aumento da CV no contexto da APS quanto à diminuição das internações sensíveis, beneficiando a população que recebe o serviço.

\section{REFERÊNCIAS}

1. Brasil. Ministério da Saúde. Secretaria de Vigilância em Saúde. Programa Nacional de Imunizações: 40 anos. [internet]. 2013. Disponível em: http://bvsms.saude.gov.br/bvs/publicacoes/programa_nacional_imunizacoes_pni40.pdf.

2. Organização das Nações Unidas. Acompanhando o desenvolvimento sustentável até 2030. [internet]. [acesso em 2020 jul 20]. Disponível em: http://www.agenda2030.org.br/acompanhe.

3. Brasil. Ministério da Saúde. Boletim Epidemiológico. Programa Nacional de Imunizações: aspectos históricos dos calendários de vacinação e avanços dos indicadores de coberturas vacinais, no período de 1980 a 2013 . Brasília, DF: 2015; 46(30). Disponível em: https://portalarquivos2.saude.gov.br/images/pdf/2015/outubro/14/besvs-pni-v46-n30. pdf

4. Waldman EA, Sato APS. Path of infectious diseases in Brazil in the last 50 years: an ongoing challenge. Rev. Saúde Públ. 2016; 50.

5. Césare N, Mota TF, Lopes FFL, Lima ACM, Luzardo R, Quintanilha LF, et al. Longitudinal profiling of the vaccination coverage in Brazil reveals a recent change in the patterns hallmarked by differential reduction across regions. Int. J. Infect. Dis.. 2020; 98:275-80.

6. Brasil. Ministério da Saúde. Portaria $n^{0} 221$, de 17 de abril de 2008. Dispõe sobre Lista Brasileira de Internações por Condições Sensíveis à Atenção Primária, no Sistema Único de Saúde - SUS. Diário Oficial da União. 17 abr. 2008.

7. Otto GLG, Silva MP de P, Costa CKF, Bernuci MP, Yamaguchi MU. Avoidable causes on the waiting list for admissions to intensive care units. Rev Rene. 2016;17(1):36-43. 
8. Roberts L. Pandemic brings mass vaccinations to a halt. Science. 2020;368(6487):116-7.

9. World Health Organization. Independent Accountability Panel for Every Woman, Every Child, Every Adolescent. 2020 Report: Caught in the COVID-19 storm: women's, children's and adolescents' health in the context of UHC and the SDGs. Geneva, 2020.

10. Brasil. Ministério da Saúde. Sistema de Informação do Programa Nacional de Imunização - SIPNI. [acesso em 2020 jul 2020]. Disponível em: http://pni.datasus.gov.br/apresentacao.asp.

11. Brasil. Ministério da Saúde. Departamento de informática do SUS (DATASUS); 2019. [acesso em 2020 jul 06]. Disponível em: tabnet.datasus.gov.br/CGI/tabcgi.exe? sim/cnv/ext10pr.def.

12. Nóvoa T d'Avila, Cordovil VR, Pantoja GM, Ribeiro MES, Cunha AC dos S, Benjamin AIM, et al. Cobertura vacinal do programa nacional de imunizações (PNI). Brazilian Journal of Health Review. 2020;3(4):7863-73.

13. Araújo MCG, Silva LF da, Baldoino LS, Porto TNR dos S, Martins V de S, Carvalho DP. Fatores que interferem no cumprimento do calendário vacinal na infância. REAS. 2020;(42):2874-2874.

14. Gomes RNS, Portela NLC, Pedrosa A de O, Cunha JDS, Monte LRS, Santos CN da C. Avaliação físico-funcional de salas de vacinas da rede pública municipal de Caxias-MA. Rev. Pesqui. (Univ. Fed. Estado Rio J., Online). 2016;3793-802.

15. Ferreira MV, Quadros A de, Dellanhese APF, Fernandes MTC. Movimento antivacinação no Facebook®:uma análise crítica da disseminação de notícias falsas. Brazilian Journal of Development. 2020;6(9):66669-85.

16. Sato APS. Qual a importância da hesitação vacinal na queda das coberturas vacinais no Brasil? Rev. Saúde Públ. 2018;52.

17. Galvão JSP, Souza MH da S, Mendes SFB. Tecnologias de saúde móvel para o aprimoramento do SIPNI. Revista JRG de Estudos Acadêmicos. 2020;11(7):177-92.

18. Silva BS, de Azevedo Guimarães EA, de Oliveira VC, Cavalcante RB, Pinheiro MMK, Gontijo TL, et al. National Immunization Program Information System: implementation context assessment. BMC Health Serv Res. 2020; (1):333.

19. Silva NS, Rachel Graciano A, Dos Santos Decembre Montalvão P, Marinho de Jesus França C. O atual e preocupante perfil epidemiológico da coqueluche no Brasil. Revista Educação em Saúde RESU. 2017; 5:21.

20. Orso LF, Chadi PF, Corrêa I. Análise retrospectiva da coqueluche na criança em dois municípios do interior de São Paulo. Rev. Enferm. Atual In Derme. 2019; 89(27).

21. Brasil. Ministério da Saúde. Boletim Epidemiológico. Hepatites Virais. Brasília, DF: 2020 [acesso em 2021 fev 11]. Disponível em: http://www.aids.gov.br/system/tdf/pub/2016/67317/boletim_hepatites_internet.pdf?file=1\&type=node\&id $=67317 \&$ force $=1$ 
22. Brito WI de, Souto FJD. Vacinação universal contra hepatite A no Brasil: análise da cobertura vacinal e da incidência cinco anos após a implantação do programa. Rev. bras. epidemiol. 2020; 23-28.

23. Reis AB, Soares BF, Alves JC, Silva NS, Oliveira MM, Almeida LS. A eficácia da vacina bcg em recém-nascidos no controle da tuberculose. Caderno de Graduação - Ciências Biológicas e da Saúde. 2019;5(3):95.

24. Cortez AO, Melo AC de, Neves L de O, Resende KA, Camargos P, Cortez AO, et al. Tuberculose no Brasil: um país, múltiplas realidades. J. bras. pneumol. 2021; 47(2).

25. Barbosa AMA, Arantes B de O, Freitas YBB de, Santana NA de A, Silva AMTC. Perfil epidemiológico das internações, gastos e mortalidade intra-hospitalar, por sequelas da tuberculose, no Brasil. REVISTA UNINGÁ. 2021;57(S1):066-7.

26. Almeida CMS, Souza LGD de, Coelho GN, Almeida KC de. Correlação entre o aumento da incidência de sarampo e a diminuição da cobertura vacinal dos últimos 10 anos no Brasil. Brazilian Journal of Health Review. 2020;3(1):406-15.

27. Medeiros EAS. Entendendo o ressurgimento e o controle do sarampo no Brasil. Acta Paul. Enferm. (Online). $2020 ; 33$.

28. Chaves ECR, Júnior K das NT, Andrade BFF de, Mendonça MHR de. Avaliação da cobertura vacinal do sarampo no período de 2013-2019 e sua relação com a reemergência no Brasil. REAS. 2020;(38) e1982.

29. Ribeiro MLC, Couto L, Mantovani DP. Sarampo: uma análise das principais causas da evolução do seu quadro epidemiológico. Revista Transformar. 2020;14(1):575-87.

30. Souza ACF de, Maia FR, Rosestolato G de A, Marques LM, Marques LM, Villela M de C. Aspectos epidemiológicos das internações por sarampo no brasil entre 2018 e 2019. Revista Saber Digital. 2020;13(2):88-98. 